Nehad Rabe'a Elbehiry

\title{
Helping Linguistics and Translation instructors Design their Exam questions According to Cognitive Theories and Testing Criteria
}

\author{
By
}

Nehad Rabe'a Elbehiry

Department of English, Damanhour University

Damanhour University, Damanhour

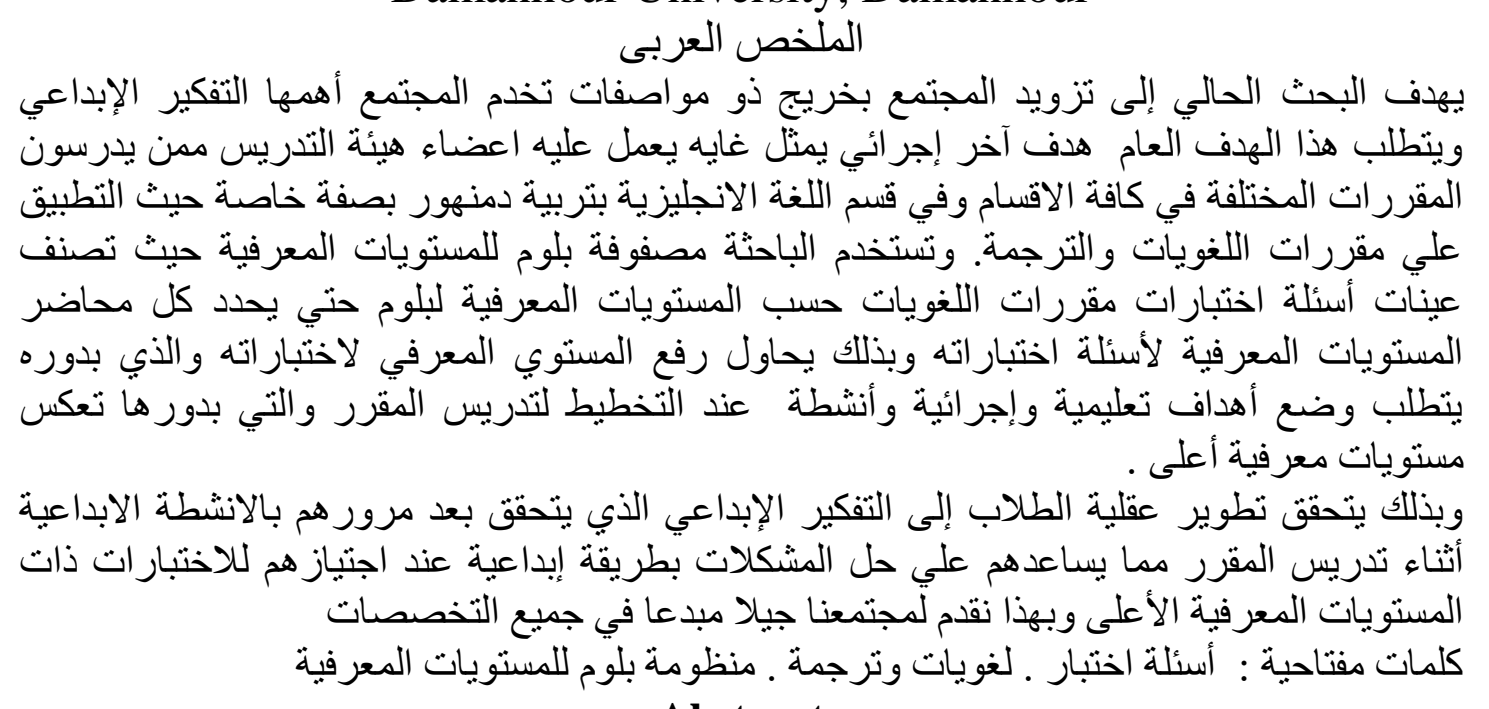

\section{Abstract}

The aim of this study is to contribute in supplying community with creative thinkers who can develop their community in a variety of majors. This encompasses one objective that requires instructors of university courses, in general, and linguistics and translation instructors, in particular, evaluate and develop their exam questions to approach higher cognitive levels. The researcher applies on a sample of linguistics and translation courses questions at English department, Damanhour university . This requires several activities to assess the current exam questions. In the present study, the researcher employs Bloom's Taxonomy on the cognitive level to evaluate and classify linguistics and translation exam questions. The cognitive domain helps in determining the real cognitive level and creativity represented by specific exam questions for each course which, in turn, requires designing such learning objectives that are consistent with this aim and objective. Instructors are recommended to plan for learning objectives that require training students on higher order thinking skills whether in class activities or assignments. This, in turn, will be reflected on students' results which will logically give a real reflection to what they have already learned. Useful recommendations are also submitted for linguistics and translation to better the cognitive level of their exam questions which contributes in presenting more creative teachers and translators to our community.

Keywords: Bloom's Taxonomy- exam questions-cognitive levels-thinking skills. 


\section{Introduction:}

The present study is an attempt to evaluate the quality of Damanhour universities' linguistics and translation exam questions in form and content by means of applying Bloom's taxonomy with specific reference to the cognitive domain. This focuses on knowledge retention starting at the simplest cognitive levels (LOTs) or low order thinking skills (i.e. Memorizing, understanding and application) and (HOTS) or high order thinking skills (i.e. analysis, synthesis and evaluation) (MASL, 2014).

The importance of the present study lies in its being a tool that allows University courses instructors in general and Linguistics and translation instructors in particular to evaluate their exam questions out of its cognitive level on one hand and out of examination criteria on the other hand. This contributes in trying to modify them to include higher cognitive levels exam questions. Exam question cognitive level modification is useful to satisfy students' individual differences.

The importance of the present study also lies in its being a tool to help English department instructors improve the quality of both their subjective and objective questions in order to add more clarity to the questions and make them accurately capable of measuring the objectives for which is designed. Moreover, this research may contribute in helping instructors of other courses in other departments and other faculties to improve their exam questions by designing them in a way to link between aim and objectives of the course and the required cognitive levels.

Research Questions can be summarized as follow :

- What are the aims and objectives reflected by translation and Linguistics exam questions in English department, Faculty of Education, Damanhour University?

- What are the teaching methods that contribute in achieving required aims and objectives for a variety of courses?

- How can we design our courses from the cognitive point of view to be consistent with the prerequisites of labour market?

- How can instructors design exam questions in a way to meet individual differences?

- What are the activities and exercises that help instructors design highercognitive level exam questions?

1.1. Bloom's Taxonomy and recent studies on exam questions

A taxonomy can be defined as "the practice and science of classification. It is a classification Table arranged in a hierarchical structure. Mathematically, a hierarchical taxonomy is a tree structure of classifications for a given set of objects. It is also named Containment 


\section{Nehad Rabe'a Elbehiry}

hierarchy. At the top of this structure is a single classification, the root node that applies to all objects. Nodes below this root are more specific classifications that apply to subsets of the total set of classified objects." (Malon, 1988)

Forehand, 2005; Krathwohl, 2002 claim that Bloom's taxonomy has been translated into 22 different languages as one of "the most frequently referred to and applied instructional design systems in the field of education, and has been used by curriculum planners, researchers, administrators, and classroom teachers at all levels of education" (Forehand, 2005).

Bloom (1956) developed a taxonomy for learning objectives to help teachers and students acquire educational experiences and to help teachers design assessment tools for the purpose of evaluating the experiences they have already learned. They agreed to categorize these educational objectives into three categories; the first works on the cognitive domain, the second works on the affective domain and the third works on the psychomotor domain. Bloom decided that the most important of these domains is the cognitive domain which is relevant to acquiring knowledge and using them in developing more searches and experiences. (ibid. in (Naomee, 2013).

(Swart, 2010; Scott, 2003; Thompson et al., 2008; Chang \& Chung, 2009) has attempted to classify exam questions based on the Bloom's taxonomy. However, there has not been much attempt in using natural language processing techniques to solve this problem. Chang \& Chung (2009) presented an online test system to classify and analyze the cognitive level of Bloom's taxonomy to English questions. The system accepts the exam question as an input, which will then be segmented. This system has a database where various verbs of Bloom's taxonomy are stored.

(Cutrone \& Chang, 2010) submit a learning management system that is capable of grading automatically once students submit their answers online. Through natural language processing, the student's answer is evaluated with semantic meaning. This is done through text preprocessing phase where the semantic meaning gets 'special space'. The product of pre-processing phase is the canonical form. Comparisons between the canonical from the student's response and the correct answer are compared to achieve the level of equivalence.

However, the works above incorporate Bloom's taxonomy in their work, they do not categorize question based on the semantic of the text. A work from Chang and Chung (2009) for example is based on keyword matching while keywords are varied over researchers. Question categorization should imply the nature of the question and how the 
questions can help educators to identify the learner's cognitive level. On the other hand, Nazlia Omar et al (2011) focus more on the semantics of the text by proposing an automated analysis of the exam questions to determine the appropriate category based on Bloom's taxonomy. Their rule-based approach applies Natural Language Processing (NLP) techniques to identify important keywords and verbs, which may assist in the identification of the category of a question. Their work focuses on the computer programming subject domain and their preliminary results indicate that the rules may successfully assist in the identification of the Bloom's taxonomy category correctly in the exam questions.

Another study focuses on the quality of exam questions in achieving the aim and objectives planned for the courses to be studied is that of Victoria Crisp et al (2016) who claim that there are three conceptions of question quality emerged and that good exam question should ; First, test the intended knowledge, understanding and skills and are clear around what is required. This means that students understand the task, allowing them to perform as well as they can. Second, it can differentiate between better and weaker students. Third, it can go beyond simple recall and understanding.

This study also benefits from the taxonomy's classification of cognitive levels by exploring the cognitive levels of exam questions selected from a variety of linguistics and translation courses at English department Damanhour University to help linguistics and translation instructors classify them also .

This in turn benefits in determining appropriate objectives for their courses and designing the activities that contributes in achieving them smoothly and finally reflect them in their exam questions. Therefore, instructors can design and modify such activities that help in achieving objectives with higher cognitive levels to help them learn easily and develop gradually. This can finally help in achieving the main aim of the course.

1.2. The importance of Bloom's Taxonomy in an Educational Community

The focus of the current study, in its main part in theory and application, is the cognitive domain because it, according to Bloom (1965), deals with recall and knowledge as well as the recognition of intellectual abilities. According to Bloom also, the cognitive domain is the domain where most of the work in curriculum development has taken place and where clear definition of objectives is mostly needed. Bloom's Taxonomy, therefore, is useful to let the instructors determine the 


\section{Nehad Rabe'a Elbehiry}

cognitive levels he already uses and develop them. On the other hand, a language instructor can also use the taxonomy to plan for specific cognitive levels for different students in different times durations during teaching.

2. Theoretical Background:

\subsection{Bloom's Taxonomy}

Bloom's creative studies and research in education resulted in three taxonomies that describe learning objectives; the cognitive taxonomy, which is related to knowledge and mental skills, the affective taxonomy which is related to feelings and attitude and the psychomotor taxonomy that is related to manual skills. The first taxonomy, which is our main area of application in the current study, is based on the cognitive domain and it consists of six levels starting from the lower level cognitive domain that reflects only retention of information and the ability to recall such information and ends in the highest level of cognitive domain that reflects higher level of thinking such as critical thinking and the ability to evaluate. Anderson (2001)

2.1.1. The cognitive Domains

$B L O O M$ S T A XONOMY

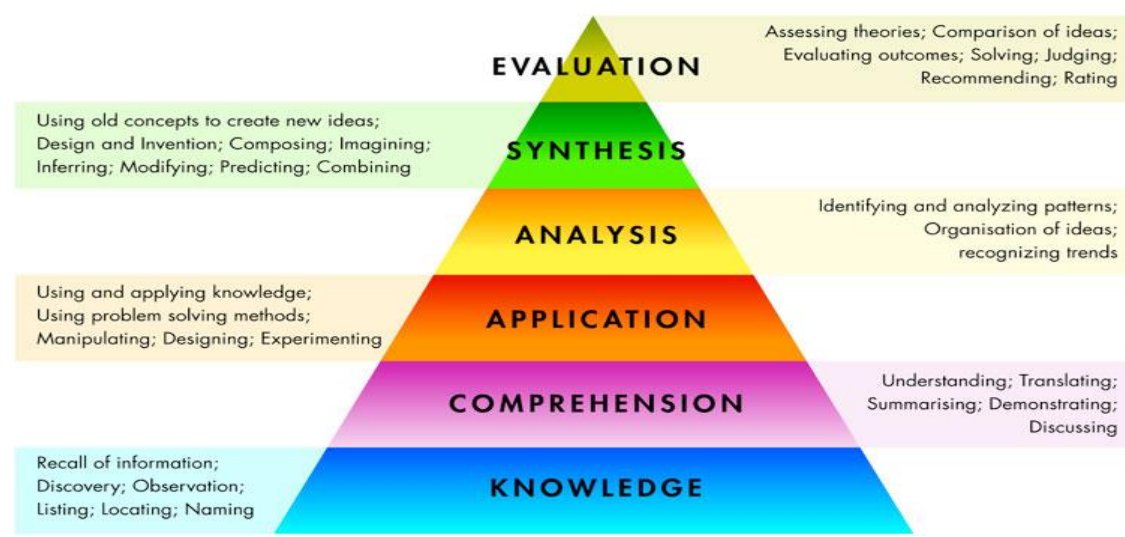

Figure 1: Bloom's Taxonomy representing the cognitive level with illustrations.

According to Bloom et al (1965), this taxonomy consists of six levels as explained on the diagram. The aim of describing them in this study is to shed light on the way each level is reflected on the exam questions designed by Damanhour universities linguistics and translation instructors and hopefully modifying them to achieve higher cognitive levels.

Knowledge: At this level, the student can memorize the information he studies. Retention of information is a characteristic of this level. A student can recall information on the long-term memory. This level is essential and basic to secure such an appropriate development at higher levels. To master this level, a student should be interested in taking notes, watching videos, listening to lectures, studying and memorizing 
terminology and rules relevant to a specific major. A teacher can expose his students to a type of questions that measures their retention of the given information such as multiple-choice questions, true and false...etc. A teacher can ensure that his students are capable of passing this level by asking them to define scientific terms, recall facts, list generalizations or categories relevant to a specific subject, list procedures to carry out a process, read, name, repeat, record information...etc. (Activities at various cognitive levels of learning, 2014)

Comprehension: At the comprehension level, the student can follow the ideas relevant to a specific subject matter when someone discusses them in front of him because he already understands them. A student, therefore, can also interpret, translate, paraphrase or summarize a subject, in a specific domain, in his own words. He can also interpret the components of a diagram, a graph, a chart...etc. into a verbal form or vice versa. This level is logically based on the knowledge acquired in the preceding level. This level also reflects the ability of the students to state the problem discussed by textbook and suggest the appropriate solutions out of his1 understanding. A teacher can measure students' understanding of a subject by asking them to locate or identify, discuss, interpret, describe a problem or restate the same problem in other words as well as to submit solutions to such problems by following appropriate techniques. Hence, a teacher can test his students by questions about problems on the comprehension level.

Application: At this level, the student uses both the knowledge he learns at the basic level and the procedures and strategies of solving a problem in a new situation. In other words, he applies what he knows and the methodology and techniques of problem solving on discussing and solving a brand-new problem without any guidance from his teacher. This level requires deeper thinking to employ what he learned in a new situation. A teacher can test his students at this level by assigning him a new problem to locate, discuss and suggest solutions by following expected steps or procedures (i.e. employing grammatical rules to solve a new sentence with an implicit problem or applying mathematical rules to solve a new problem)

Analysis: This level requires both knowledge and understanding. However, it does not merely require the application level but requires prompting by the teacher to follow his development. A teacher can test his students by asking them to analyze the components of a situation, a problem, a figure, a subject... etc. At this level, a student will be able to justify his answers and clarify why his solution works in a specific 


\section{Nehad Rabe'a Elbehiry}

problem. In other words, the student stands in a strong position to defend the results he achieved. He can examine, compare and contrast theories and differentiate different solutions of different problems.

Synthesis: This level requires the preceding four levels; knowledge, comprehension, application and analysis. It requires a guidance and follow up at the side of the teacher. At this level, a student needs to learn how to assemble parts into a whole by means of creative thinking. He can suggest his own procedures to solve a new problem. He can also make a new piece of writing about a specific subject. A teacher can test the ability of his students to pass this level by asking him to design a diagram, to submit a project plan, to propose a new design. We can say that there is a big similarity between this level and the comprehension level since the student needs to demonstrate and explain his new plan for example. However, the difference lies in his demonstration of his new own project that he designed himself. This level is also characterized with more depth.

Evaluation : This level requires all the preceding five levels to be carried out. It resembles the comprehension level to a great deal. However, the difference lies in the degree of depth in which the student should demonstrate his design or project. At this level, the student should be able to evaluate a piece of work or a design by giving a value judgment based on its being useful or effective. He should analyze the components of a design to evaluate its consistency. A student should be able to evaluate a product out of internal criteria, such as accuracy and consistency, and external criteria such as cost and appropriateness to carry out the goals for which it is designed. He should also be able to report the feasibility of a product in such a presentation that is characterized in more depth and richer content. A teacher, hence, can ensure that his students are able to evaluate a situation or a product by asking them to assess, evaluate and compare competing opinions relative to a specific problem or design prior to submitting his own judgment.

2.2. Bloom's Taxonomy Revised

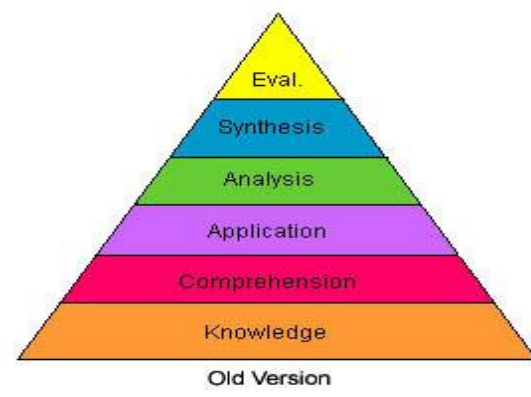

Figure 2Terminology changes

(Bloom's taxonomy, 2014)

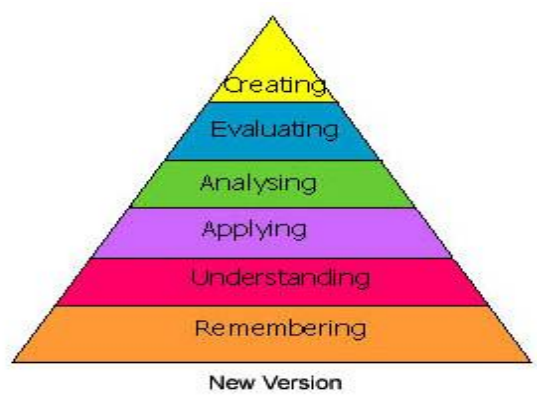

New Version 
Figure 3: The difference between the old version and the new revised version of Bloom's taxonomy on the cognitive domain

As demonstrated above in the acknowledgement with Bloom's taxonomy that Benjamin Bloom (1956) "headed a group of educational psychologists who developed a classification of levels of intellectual behavior important in learning. During the 1990's a new group of cognitive psychologists, led by Lorin Anderson (a former student of Bloom), updated the taxonomy to reflect relevance to 21 st century work. The two graphics show the revised and original Taxonomy. "Note the change from nouns to verbs associated with each level." (Schultz, 2014).

It is also observed that in the new revised taxonomy, the nouns are not only changed into action verbs, which reflects more active thinking, but also the order of the final two levels have been exchanged. Many psychologists, therefore, think that the new taxonomy improved the usability of the original taxonomy and made it more accurate. In Krathwohl and Anderson's revised taxonomy, Anderson (2014) "the authors combine the cognitive processes with the above three levels of knowledge to form a matrix. In addition, they added another level of knowledge - metacognition" and then metacognition is defined as "Knowledge of cognition in general, as well as awareness and knowledge of one's own cognition." (ibid.)

\section{Application}

In this part of the study application on the selected data is presented with accompanying analysis both for exam questions and results.

\subsection{Methodology}

The current study is based on the descriptive method in which the researcher describes the results of applying Bloom's taxonomy on the given sample of exam questions. The results will be described both on the quantitative level and qualitative level; a thematic analysis will be employed too. According to the online dictionary of social sciences, qualitative data is defined as:

"Research using methods such as participant observation or case studies which result in a narrative, descriptive account of a setting or practice. Sociologists using these methods typically reject positivism and adopt a form of interpretive sociology" http://bitbucket.icaap.org/

Nkwi, Nyamongo, and Ryan (2001) submit a clearer definition of qualitative research that it "involves any research that uses data that do not indicate ordinal values". On the other hand, quantitative research, according to Bernard (1996), includes interpretation of patterns in 


\section{Nehad Rabe'a Elbehiry}

numeric data while qualitative research includes interpretation of meaning in text or images. In the current study, quantitative data is to be used based on qualitative analysis. This side of qualitative analysis is not explicit in the definitions to qualitative analysis. According to Neuendorf (2001), qualitative research analysis has two approaches; the explanatory approach, which is content-driven and the confirmatory approach which is hypothesis driven.

In this study, exam questions are the data representing the text required to be classified into a specific cognitive level by means of Bloom's cognitive level. Then, the number of questions in each level for each major are given the equivalent percentage. Then comparison between the variety of levels takes place to evaluate the cognitive levels for each category of exam questions.

\subsection{Data and Sample collected for Application}

The data employed for the purpose of the present study includes the exam questions of Damanhour universities Linguistics and translation exam questions for a whole academic year in two semesters and they are categorized in the following way:

Linguistics exam questions (i.e. exam questions for courses such as: phonology, morphology, Syntax, Grammar, Reading, Writing, Essay writing)

Translation exam questions

\section{Results and Recommendations}

This part of the study is specified to present results relevant to classifying exam questions into their equivalent cognitive levels according to Bloom's taxonomy. This part also presents an analysis of students' results for the same exam questions.

4.1. Results achieved by the study

In this part of the study, exam questions are classified into two categories (i.e. Translation and Linguistics) and the exam questions in each category are also categorized into the cognitive levels they represent. The researcher reads every question and classifies it according to its cognitive level. The total number of questions in each cognitive level has been calculated and the percentage of each cognitive level for each of the two categories has also been calculated. Finally, the variety of percentages for each level for each category are compared. 
Helping Linguistics and Translation instructors Design their Exam questions According to Cognitive Theories and Testing Criteria

\section{Translation courses}

Table 1:Cogintive levels in Translation courses exam questions

\begin{tabular}{|l|l|l|l|l|l|l|l|}
\hline $\begin{array}{l}\text { Cognitive } \\
\text { level }\end{array}$ & $\begin{array}{l}1 . \text { Knowled } \\
\text { ge }\end{array}$ & $\begin{array}{l}2 . \text { Comprehen } \\
\text { sion }\end{array}$ & $\begin{array}{l}\text { 3.Applicat } \\
\text { ion }\end{array}$ & $\begin{array}{l}4 . \text { Analy } \\
\text { sis }\end{array}$ & $\begin{array}{l}\text { 5.Synthe } \\
\text { sis }\end{array}$ & $\begin{array}{l}\text { 6.Evaluatio } \\
\text { n }\end{array}$ & TOTAL \\
\hline $\begin{array}{l}\text { No. of } \\
\text { questions }\end{array}$ & 40 & 15 & 35 & 10 & 5 & ZERO & 105 \\
\hline Percentage & $38 \%$ & $14.3 \%$ & $33.3 \%$ & $9.5 \%$ & $4.9 \%$ & ZERO $\%$ & $100 \%$ \\
\hline
\end{tabular}

Table 2: Model exam questions rubrics in Translation courses.

\begin{tabular}{|c|c|c|c|c|c|c|}
\hline $\begin{array}{l}\text { Cogniti } \\
\text { ve level }\end{array}$ & 1.Knowledge & 2.Comprehension & 3.Application & 4.Analysis & 5.Synthesis & 6.Evaluation \\
\hline $\begin{array}{l}\text { Model } \\
\text { question }\end{array}$ & $\begin{array}{l}\text {-write short } \\
\text { notes on... } \\
\text {-give the } \\
\text { equivalent of } \\
\text { the following } \\
\text { terms } \\
\text { lexpression } \\
\text { into Arabic } \\
\text {-write the } \\
\text { missing words } \\
\text { in the } \\
\text { following } \\
\text { statements } \\
\text {-define (FIVE) } \\
\text { only of the } \\
\text { following } \\
\text { terminologies } \\
\text {-fill in the } \\
\text { following table } \\
\text { with suitable } \\
\text { translations }\end{array}$ & $\begin{array}{l}\text {-mention the } \\
\text { strategies used } \\
\text { by the } \\
\text { professional } \\
\text { translators for } \\
\text { non- equivalence } \\
\text {-match each item } \\
\text { in column (A) } \\
\text { with the suitable } \\
\text { item in column } \\
\text { (B)....... } \\
\text {-write (True) in } \\
\text { front of correct } \\
\text { statements and } \\
\text { (False) in front } \\
\text { of the wrong } \\
\text { statements } \\
\text {-correct the } \\
\text { following false } \\
\text { statements }\end{array}$ & $\begin{array}{l}\text {-translate the } \\
\text { following } \\
\text { into Arabic } \\
\text {-translate the } \\
\text { following } \\
\text { into English }\end{array}$ & $\begin{array}{l}\text {-read the } \\
\text { sentences } \\
\text { of the } \\
\text { following } \\
\text { paragraph } \\
\text { to correct } \\
\text { their } \\
\text { grammatic } \\
\text { al } \\
\text { spelling } \\
\text { and } \\
\text { punctuatio } \\
\text { n mistakes }\end{array}$ & $\begin{array}{l}\text { - Read the } \\
\text { following } \\
\text { MT and } \\
\text { edit into } \\
\text { correct } \\
\text { text }\end{array}$ & \\
\hline
\end{tabular}

\section{Linguistics courses}

Table 1: Cognitive levels in Linguistics courses exam questions

\begin{tabular}{|l|l|l|l|l|l|l|l|}
\hline $\begin{array}{l}\text { Cognitive } \\
\text { level }\end{array}$ & $\begin{array}{l}\text { 1.Knowled } \\
\text { ge }\end{array}$ & $\begin{array}{l}2 . \text { Comprehe } \\
\text { nsion }\end{array}$ & $\begin{array}{l}\text { 3.Applicat } \\
\text { ion }\end{array}$ & $\begin{array}{l}4 . \text { Analy } \\
\text { sis }\end{array}$ & $\begin{array}{l}\text { 5.Synthe } \\
\text { sis }\end{array}$ & $\begin{array}{l}\text { 6.Evaluatio } \\
\text { n }\end{array}$ & TOTAL \\
\hline $\begin{array}{l}\text { No. of } \\
\text { questions }\end{array}$ & 87 & 93 & 65 & 52 & 45 & 8 & 350 \\
\hline Percentage & $24.9 \%$ & $26.6 \%$ & $18.6 \%$ & $14.9 \%$ & $12.8 \%$ & $2.2 \%$ & $100 \%$ \\
\hline
\end{tabular}




\section{Nehad Rabe'a Elbehiry}

Model exam question roots in linguistics courses :

Table 2: Model exam questions in Linguistics courses.

\begin{tabular}{|c|c|c|c|c|c|c|}
\hline $\begin{array}{l}\text { Cognitiv } \\
\text { e level }\end{array}$ & 1.Knowledge & 2.Comprehension & 3.Application & 4.Analysis & 5.Synthesis & $\begin{array}{l}\text { 6.Evaluatio } \\
n\end{array}$ \\
\hline $\begin{array}{l}\text { Model } \\
\text { question }\end{array}$ & $\begin{array}{l}\text { Complete the } \\
\text { following } \\
\text { sentences } \\
\text {-define inaudible } \\
\text { plosion and then } \\
\text { transcribe these } \\
\text { words to show } \\
\text { the inaudible } \\
\text { plosion } \\
\text {-write the } \\
\text { missing words in } \\
\text { order } \\
\text { complete the } \\
\text { following } \\
\text { sentences } \\
\text {-what is } \\
\text { traditional } \\
\text { grammar? } \\
\text {-match these } \\
\text { statements with } \\
\text { their } \\
\text { completions }\end{array}$ & $\begin{array}{l}\text { True or false } \\
\text { :correct the false } \\
\text { statement } \\
\text {-fill in the blanks } \\
\text { with the correct } \\
\text { answers } \\
\text {-discuss the } \\
\text { difference in } \\
\text { meaning in the } \\
\text { sentence below } \\
\text {-complete the } \\
\text { sentences with } \\
\text { appropriate } \\
\text { pronouns. } \\
\text {-circle the letter of } \\
\text { the correct } \\
\text { completion for the } \\
\text { following } \\
\text { sentences } \\
\text { Indicate the terms } \\
\text { associated with } \\
\text { these meanings }\end{array}$ & $\begin{array}{l}\text {-underline } \\
\text { verb that } \\
\text { agrees with } \\
\text { the subject in } \\
\text { each sentence } \\
\text {-complete the } \\
\text { sentence } \\
\text { with....... } \\
\text {-change these } \\
\text { active } \\
\text { sentences to } \\
\text { passive } \\
\text {-use the form } \\
\text { of passive } \\
\text { specified in } \\
\text { parentheses } \\
\text {-write the } \\
\text { plural form of } \\
\text { each noun in } \\
\text { parentheses } \\
\text {-make the } \\
\text { italicized } \\
\text { nouns } \\
\text { possessive by } \\
\text { adding } \\
\text { apostrophe... } \\
\text {.. - } \\
\text {-write ONE } \\
\text { example for } \\
\text { the followings } \\
\text {-read the } \\
\text { paragraph } \\
\text { below 6and }\end{array}$ & $\begin{array}{l}\text { Use the } \\
\text { bracketed } \\
\text { analysis to } \\
\text { analyze the } \\
\text { following } \\
\text { structure } \\
\text {-break down } \\
\text { the words } \\
\text { below into } \\
\text { basic } \\
\text { morphemes } \\
\text {-identify six } \\
\text { different } \\
\text { functional } \\
\text { morphemes }\end{array}$ & $\begin{array}{l}\text { Change the } \\
\text { sentences } \\
\text { below the } \\
\text { polite } \\
\text { requests } \\
\text { using the } \\
\text { words in } \\
\text { parenthese } \\
\text { s } \\
\text {-use a form } \\
\text { of other to } \\
\text { complete } \\
\text { the } \\
\text { sentence } \\
\text {-complete } \\
\text { the } \\
\text { sentences } \\
\text { using the } \\
\text { italicized } \\
\text { noun as a } \\
\text { modifier } \\
\text {-provide } \\
\text { the } \\
\text { informatio } \\
\text { n for the } \\
\text { following } \\
\text { issues }\end{array}$ & \\
\hline
\end{tabular}

The following table shows model exam question roots already represented by Translation courses

Figure 4: Cognitive levels of exam questions represented and compared

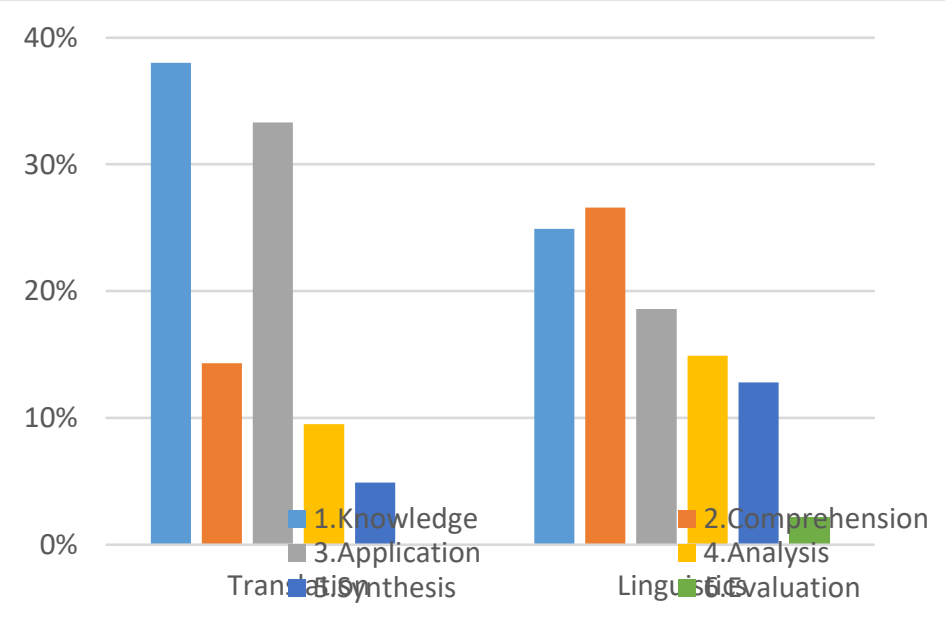


The preceding graph represents the variant cognitive levels in the two categories (i.e. Linguistics and Translation). This graph together with the preceding tables are useful in concluding the following results In translation courses as represented, it is clear that knowledge level is the highest since it is $38 \%$. Translation instructors admit that this level is relatively high because it reflects questions relevant to the knowledge of the theoretical part in translation courses that depends more on recalling the definitions of translations types, the role of a translator, the definition of translation as a process...etc. On the other hand, They consider theoretical background questions in translation with a minor role for translation courses. Therefore, they do not give it such interest and they focus more on translating texts practice.

On the other hand, the second cognitive level that reflects students' understanding of what they have studied is clearly lower than knowledge level $(14.3 \%)$.

In translation courses also, the third level that shows application is relatively high (33.3\%) because translation depends more on applying translation theories on new texts. Here, we can say that the nature of the

course governs the type of questions and cognitive levels inherited in most exam questions.

The fourth cognitive level, the analysis level and the fifth, the synthesis level are relatively low although some questions in translation courses require analysis of mistaken translations.

In translation courses, the (LOTs) or low order thinking skills questions are more than (HOTs) or high order thinking skills. Moreover, the highest thinking skill of Bloom's cognitive taxonomy , the evaluation level has $0 \%$ in translation courses. Therefore, it is suggested to care more for such types of questions that arise creative thinking for students such as asking students to analyze or evaluate TTs translated by different translators.

In Linguistics courses: The results seem different from translation courses. This shows a variety in cognitive levels reflected by exam questions.

The first (i.e. knowledge) and second (i.e. comprehension) cognitive levels are highly reflected by exam questions.

The third cognitive level (i.e. application) and the fourth (i.e. analysis) are reflected in a lower percentage than the first and second levels.

The fifth cognitive level (i.e. synthesis) is very low (12.8\%) compared to the percentages of the other levels. However, it is higher than the synthesis level compared to translation courses. 


\section{Nehad Rabe'a Elbehiry}

Although evaluation level is too low (2.2\%) in comparison to the other cognitive levels, it exists in linguistics courses where it does not exist in translation courses.

The synthesis level is relatively low $(4.1 \%)$

Hence, we conclude that all the courses of (Translation and linguistics ) use (LOTs) in the majority of their exam questions. However, translation courses do not employ exam questions that encompass evaluation.

Linguistics courses employ exam question of evaluation nature more than translation courses.

Table 3: Translation courses Using higher cognitive levels in some of their exam questions

The following tables show the courses that use higher cognitive levels in of their exam questions

\begin{tabular}{|l|l|l|l|}
\hline $\begin{array}{l}\text { Higher level cognitive } \\
\text { level }\end{array}$ & 4.Analysis & 5.Synthesis & 6.Evaluation \\
\hline Courses included & $\begin{array}{l}\text {-Translation into } \\
\text { English } \\
\text { Translation into Arabic }\end{array}$ & $\begin{array}{l}\text {-Translation into } \\
\text { English }\end{array}$ & \\
\hline
\end{tabular}

Table 4: Linguistic courses using higher cognitive levels in some of their exam questions

\begin{tabular}{|c|c|c|c|}
\hline $\begin{array}{l}\text { Higher level } \\
\text { cognitive level }\end{array}$ & 4.Analysis & 5.Synthesis & 6.Evaluation \\
\hline $\begin{array}{l}\text { Courses } \\
\text { included }\end{array}$ & $\begin{array}{l}\text {-Grammar } \\
\text {-study skills } \\
\text {-reading skills } \\
\text {-reading techniques } \\
\text {-basics of writing } \\
\text {-advanced writing } \\
\text {-paragraph writing } \\
\text {-morphology } \\
\text {-essay writing } \\
\text {-preparation } \\
\text { international tests } \\
\text {-introduction to linguistics } \\
\text {-advanced reading }\end{array}$ & $\begin{array}{l}\text {-study skills } \\
\text {-discussion in } \\
\text { English } \\
\text {-English language } \\
\text { vocabulary } \\
\text {-situational language } \\
\text {-basics of writing } \\
\text {-reading skills } \\
\text {-English phonetics } \\
\text {-basic grammar } \\
\text {-advanced writing } \\
\text {-paragraph writing } \\
\text {-morphology } \\
\text {-essay writing } \\
\text {-history of the } \\
\text { English language } \\
\text {-sociolinguistics } \\
\text {-grammar }\end{array}$ & $\begin{array}{l}\text {-reading skills } \\
\text {-advanced writing } \\
\text {-paragraph writing }\end{array}$ \\
\hline
\end{tabular}




\subsubsection{Analysis of exam questions results}

As a part and parcel of submitting objective and valid results to the current research, students' results are submitted. The following results are obtained from the records of English Language Department to contribute in supplying a valid result analysis specially because they represent students' results relevant to the very exam questions analyzed in the preceding section. In fact, results analysis is vital and complementary to exam questions cognitive levels analysis. The results reflect what students have achieved from the learning outcomes designed previously by their instructors. They are considered a representation of the exam questions levels which are the focus of the present study. They can be represented in the following way:

\section{Linguistics}

Morphology

Table 5:grade range in Morphology course

\begin{tabular}{|l|l|l|l|l|l|l|l|}
\hline Value & A & B & C & D & F & Success & $\begin{array}{l}\text { Total } \\
\text { students } \\
\text { no. }\end{array}$ \\
\cline { 1 - 7 } Grades & $90-100$ & $89-80$ & $79-70$ & $69-60$ & $59-0$ & $60-100$ & 53 \\
\hline Students no. & 4 & 14 & 7 & 11 & 17 & 36 & $76 \%$ \\
\hline percentage & $8 \%$ & $26 \%$ & $13 \%$ & $21 \%$ & $32 \%$ & \\
\hline
\end{tabular}

In linguistics category, Morphology course is one of the courses that shows higher level of failure (32\%). This may be a result of assigning higher cognitive level questions. The percentage of A value is only (8\%). Creative Writing E221

Table 6: Grades range in Creative Writing E221 course

\begin{tabular}{|l|l|l|l|l|l|l|l|}
\hline Value & A & B & C & D & F & $\begin{array}{l}\text { Succe } \\
\text { ss }\end{array}$ & $\begin{array}{l}\text { Total } \\
\text { students } \\
\text { no. }\end{array}$ \\
\cline { 1 - 6 } grades & $\begin{array}{l}90- \\
100\end{array}$ & $89-80$ & $79-70$ & $69-60$ & $59-0$ & $\begin{array}{l}60- \\
100\end{array}$ & 109 \\
\cline { 1 - 5 } Students & 5 & 16 & 29 & 48 & 11 & 98 & 109 \\
\cline { 1 - 5 } percentage & $5 \%$ & $15 \%$ & $27 \%$ & $44 \%$ & $10 \%$ & $90 \%$ & \\
\hline
\end{tabular}

Although writing (3) E327 requires higher cognitive level in which a student can synthesize new ideas in new topics in his own style, the percentage of success is relatively high $(90 \%)$ although A value percentage is only $(5 \%)$. 


\section{Nehad Rabe'a Elbehiry}

Writing (3) E327

Table 7: Grades range in writing (3) E327 course

\begin{tabular}{|l|l|l|l|l|l|l|l|}
\hline Value & A & B & C & D & F & Success & $\begin{array}{l}\text { Total } \\
\text { students } \\
\text { no. }\end{array}$ \\
\cline { 1 - 6 } Grades & $90-100$ & $89-80$ & $79-70$ & $69-60$ & $59-0$ & $60-100$ & 138 \\
\hline Students no. & 2 & 10 & 25 & 39 & 62 & 76 & \\
\hline percentage & $1 \%$ & $7 \%$ & $18 \%$ & $28 \%$ & $45 \%$ & $55 \%$ & \\
\hline
\end{tabular}

Out of the percentages of 'Creative Writing' course results, the level of failure is relatively high (45\%) and the percentage of excellent is too low (1\%). This may be a result of using higher cognitive levels in 'Creative Writing E221' exam questions without training students on such type of questions. It is also clear that the percentage of results between $80 \%$ and $90 \%$ is also low $(7 \%)$

\section{Linguistics E421}

Table 8: Grades range in Linguistics E421course

\begin{tabular}{|c|c|c|c|c|c|c|c|}
\hline Value & $\mathrm{A}$ & B & $\mathrm{C}$ & $\mathrm{D}$ & $\mathrm{F}$ & Success & Total \\
\hline Grades & $90-100$ & $89-80$ & $79-70$ & $69-60$ & $59-0$ & $60-100$ & students no. \\
\hline Students no. & 4 & 6 & 16 & 52 & 38 & 78 & 116 \\
\hline Percentage & $3 \%$ & $5 \%$ & $14 \%$ & $45 \%$ & $33 \%$ & $67 \%$ & \\
\hline
\end{tabular}

In 'Linguistics E421' course, the students' results show high failure percentage as (33\%) and the excellent percentage is also low (3\%) which may also be a result of using higher cognitive level exam questions. It is clear also that the percentage of results between $80 \%$ and $90 \%$ is also low which confirms this conclusion.

Writing (4) E427

Table 9:Grades Range in Writing course (4) E427.

\begin{tabular}{|c|c|c|c|c|c|c|c|}
\hline Value & $\mathrm{A}$ & B & $\mathrm{C}$ & $\mathrm{D}$ & $\mathrm{F}$ & Success & Total \\
\hline Grades & $90-100$ & $89-80$ & $79-70$ & 69-60 & $59-0$ & $60-100$ & students no. \\
\hline Students no. & 8 & 4 & 15 & 19 & 5 & 46 & 51 \\
\hline Percentage & $16 \%$ & $8 \%$ & $29 \%$ & $37 \%$ & $10 \%$ & $90 \%$ & \\
\hline
\end{tabular}

It seems that Writing (4) E427 course has a very high success percentage $(90 \%)$ as well as relatively high Excellent percentage (16\%) although this course is more advanced and more difficult than Creative writingE122 course. This may be explained by giving students a wide range of options in the exam paper or limiting the topics before exam. 
English Grammar (1) E122

Table 10: Grades range in English Grammar E122 course.

\begin{tabular}{|l|l|l|l|l|l|l|l|}
\hline Value & A & B & C & D & F & Success & Total \\
Studes & $90-100$ & $89-80$ & $79-70$ & $69-60$ & $59-0$ & $60-100$ & studs no. \\
\hline Students no. & 0 & 3 & 20 & 18 & 0 & 41 & 41 \\
\hline Percentage & $0 \%$ & $7 \%$ & $49 \%$ & $44 \%$ & $0 \%$ & $100 \%$ & \\
\hline
\end{tabular}

In 'English Grammar E122' course, although the success percentage is $(100 \%)$, the Excellent percentage is $(0 \%)$ and the results between 80 and 90 is only (7\%). This shows that most of the students have achieved an average level of cognitive levels. In other words, they are incapable of approaching the higher cognitive levels. This may also lead to the conclusion that the higher cognitive levels already present in exam questions, but students could not achieve them because they were not trained on such types of questions or because the students' level may be that low. In fact, the students' low grades in 'Grammar E122' is also relevant to their low grades in 'Writing' courses.

Applied Linguistics E425

Table 11:Grades range in Applied Linguistics E425 course

\begin{tabular}{|l|l|l|l|l|l|l|l|}
\hline Value & A & B & C & D & F & Success & $\begin{array}{l}\text { Total } \\
\text { students } \\
\text { no. }\end{array}$ \\
\cline { 1 - 6 } Grades & $90-100$ & $89-80$ & $79-70$ & $69-60$ & $59-0$ & $60-100$ & 101 \\
\hline Students no. & 15 & 29 & 29 & 25 & 13 & 88 & \\
\hline Percentage & $15 \%$ & $29 \%$ & $29 \%$ & $25 \%$ & $13 \%$ & $87 \%$ & \\
\hline
\end{tabular}

In 'Applied Linguistics E425' course, although the success percentage is $87 \%$, the Excellent percentage is relatively high (15\%). The percentage of the results between $80 \%$ and $90 \%$ is relatively high $(29 \%)$. The percentage of failure is also not that low (13\%). This may refer to the individual differences between students.

Discourse analysis (E323)

Table 12:Grades range in Discourse Analysis course (E323)

\begin{tabular}{|l|l|l|l|l|l|l|l|}
\hline Value & A & B & C & D & F & Success & Total \\
students no. \\
\hline Grades & $90-100$ & $89-80$ & $79-70$ & $69-60$ & $59-0$ & $60-100$ & 68 \\
\hline Students no. & 4 & 15 & 17 & 26 & 6 & 62 & 68 \\
\hline Percentage & $6 \%$ & $22 \%$ & $25 \%$ & $38 \%$ & $9 \%$ & $91 \%$ & \\
\hline
\end{tabular}

In 'Discourse Analysis' course, the success percentage is very high $(91 \%)$ against $(9 \%)$ of Failure percentage. There is also $(6 \%)$ percent of Excellent as well as (9\%) of failure. Most of the students; grades are in the average area. This may be a result of the nature of the course itself which requires a considerable level of communication and interaction with oral expression more than any other course. 


\section{Nehad Rabe'a Elbehiry}

\section{Translation}

Translation into English (E224)

Table 13: Grades range Translation into English E224

\begin{tabular}{|l|l|l|l|l|l|l|l|}
\hline Value & A & B & C & D & F & Success & Total \\
students no.
\end{tabular}

Translation into Arabic E126

Table 14: Grades range Translation into Arabic E126.

\begin{tabular}{|l|l|l|l|l|l|l|l|}
\hline Value & A & B & C & D & F & Success & Total \\
students no. \\
\hline $\begin{array}{l}\text { Grades } \\
\text { Students }\end{array}$ & $90-100$ & $89-80$ & $79-70$ & $69-60$ & $59-0$ & $60-100$ & 62 \\
\hline Percentage & $4 \%$ & 11 & 19 & 23 & 7 & 55 & 62 \\
\hline
\end{tabular}

The results of 'Translation into Arabic E126' course seem considerable in comparison to the results of the preceding course. The nature of this course is not that difficult such as 'Translation into English E224'. The Success percentage is not very high (89\%) against (11\%) Failure. It is observed that most of the success percentage lies in the average area. The Excellent percentage is very low (2\%) which refers to the existence of higher cognitive levels in exam questions and the capability of few students to carry out (HOTs).

Translation (3) E324

Table 15: Grades range in Translation (3) E324

\begin{tabular}{|l|l|l|l|l|l|l|l|}
\hline Value & A & B & C & D & F & Success & Total \\
students no.
\end{tabular}

In 'Translation (3) E324 course', the percentages seem to approach the percentages of 'Translation into English E224' course which is also considered one of the advanced courses among translation courses. The Success percentage is very high $(92 \%)$ against (7\%) Failure. Moreover, the Excellent percentage is $(18 \%)$ and the grades between $80 \%$ and $90 \%$ is also relatively high $(27 \%)$. Therefore, these results can be given the same conclusions of 'Translation into English E224' course.

Translation (4) E423

Table 16:Grades range in Translation (4) course E423 .

\begin{tabular}{|l|l|l|l|l|l|l|l|}
\hline Value & A & B & C & D & F & Success & Total \\
Students no.
\end{tabular}


In ' Translation into Arabic E126' course results, although the course is relatively simple because it is to be studied by beginners in early levels and it submits simple theoretical background as well as simple texts for applying "translation (4) 423", the results are not that high. For example, the Success percentage is not that high (75\%) against (25\%) Failure percentage. The percentage of the grades between $80 \%$ and $90 \%$ is not that high also (19\%). This can be explained either by the exam questions' inclusion of higher cognitive levels or the low academic level of students which makes most of them incapable of carrying out (HOTs) or even (LOTs)'s three cognitive levels.

\subsection{Discussion of Results}

Before discussing the results attained by the study we can say in general that instructors assigned to teach specific linguistic courses are better recommended to determine general learning outcomes for each course as well as determining them to each lecture as well as supporting them with appropriate and interesting activities. Learning outcomes accurately determine the required cognitive levels and the required cognitive level to carry out the assigned course. Students' performance reflects their cognitive level as well as the cognitive levels they have attained. In Because examination is a useful tool to assess students' performance. It helps instructors also to evaluate their performance also during teaching and modifying the objectives by submitting a variety of activities. This is reflected later in their achievement of higher cognitive levels by answering more difficult question requiring synthesis or evaluation for example. This is represented by the cognitive levels they attained and depends mainly on the exam questions presented in the exam paper (Jones, Sch. of Eng., Harland, Reid, \& Bartlett, 2009). Therefore, Bloom's taxonomy on the cognitive level is employed as a tool to measure the size of cognitive levels in exam papers, which in turn reflects the learning outcomes designed by instructors.

Action verbs in each exam question are considered the keywords to the cognitive level it represents. Hence, Bloom's taxonomy, in its six cognitive levels, is used as a tool to classify exam questions into six categories according to the six cognitive levels. Hence, the size of each cognitive level in exams is determined easily and this, accordingly, facilitates its description and comparison between the variant levels in the variety of courses. Therefore, using the descriptive explanatory approach is useful as being based on observation of facts and not hypothesis. Exam results of the same questions are also described as a reflection on students' achievement of both learning outcomes and cognitive levels. 
In the current study, it is observed that the Knowledge and Comprehension cognitive levels are the commonest levels existing in all exam questions. It is essential to use them in all courses because they are considered as a background for all the following levels on one hand. On the other hand, their existence is important for students whose capacities are limited and for those who are incapable of achieving higher cognitive levels. They are important to satisfy individual differences among students.

However, if we assume that most of the exam questions include higher order thinking skills (HOTs) and ignoring lower order thinking skills (LOTs), a considerable number of students with limited capacities may suffer and fail in most of the courses. The problem arises when specific courses do not include higher cognitive plan in their learning outcomes. This results in lack of training to students on (HOTs) who become satisfied only with (LOTs). This is normally reflected in exam questions that do not cover higher cognitive levels. For such courses, the results may be very high despite the complexity of the courses in general.

Another problem arises regarding the submission of questions that seem of higher cognitive levels, however reflecting lower cognitive levels (i.e. knowledge). This occurs when the students are given a background idea about the topics to be submitted in Writing courses for example or when the Translation questions which require higher cognitive levels in criticizing problematic target text (TT) or synthesizing a correct one, are seen or translated previously in class. This directly transforms the status of exam question from (HOTs) to (LOTs), which is not recommended for valid exam results. In other words, some questions seem as if advanced and including higher cognitive

levels from their action verbs, but in fact it is the reverse. The problem of this type of questions is that they do not distinguish creative thinkers.

If we compare the categories representing linguistics and Translation exam questions, we conclude that sometimes the nature of the course governs the cognitive level of exam questions. The nature of Linguistics courses, for example, includes higher cognitive levels in a considerable number of their exam questions because such courses encompass applications on rules for courses such as Grammar, Phonetics, Morphology and Phonology. Therefore, Linguistics courses include at least the first four cognitive levels. As for Translation courses, they are of 'application' nature. They include application level, which is the first of the three higher cognitive levels. Translation courses exam questions require translation into Arabic or into English are basic questions in all translation courses. They lead to higher cognitive levels because students 
start with interpretation of the message of the ST then render it into another language which requires synthesis as well. Moreover, translation courses questions which require criticizing problematic TTs or machine translation texts into Arabic or into English may also require the highest cognitive levels of evaluation by finding out the mistakes and the reasons underlying translation problems. They become more effective also if they require explaining the origin of translation problem by reflecting on theoretical background as well as formulating a better target text. Therefore, translation instructors are recommended to arise critical thinking in their students by introducing problematic translations to fix.

The researcher did her best in applying Bloom's taxonomy and concluding the results by classifying given exam questions according to the six cognitive levels. In fact, employing Bloom's cognitive taxonomy contributes in helping instructors recognize the status of his /her exam questions relevant to the actual cognitive levels represented by his/her exam questions. This benefits in reviewing and modifying the learning objectives designed before teaching. He may formulate such learning objectives which allow more practice and creativity in which students can use higher level thinking skills. Consequently, this leads to designing such exam questions that encompass higher cognitive levels. Therefore, a teacher can submit such exam questions that meet all cognitive levels in order to distinguish creative thinkers and inspire others.

Although the results obtained contribute in classifying exam questions and their reflection in student's exam results, there are other external factors that may affect the accuracy and validity of students' results. These factors are to be assigned to social or educational factors. Among the factors that may interrupt students' comprehensive achievement of higher cognitive levels may be his /or her repeated absence or attending late to lectures. Another factor may be weak motivation which may be a result of a student's ignorance to the main aim and objectives of the courses he studies and its importance to labour market. Other reasons may be of environmental or financial nature such as his home's being too far from the University campus together which results in wasting a lot of time on the way. This may result in exhausted students who are incapable of creative thinking. Financial reasons are also effective when a student is incapable of obtaining specific materials for study such as internet as well as other facilities. Although these reasons are not the focus of this study, but the instructors should pay heed to them while planning for his learning objectives and exam questions. This gives him a comprehensive vision for all the factors affecting the learning process and hence he can 


\section{Nehad Rabe'a Elbehiry}

do his best to meet the variety of individual differences in the learning activities, assignments, projects, exam questions...etc.

4.3. Recommendations for better Exam quality

Out of the preceding analysis of exam questions and students' results in linguistics and translation courses taught in English Language Department by means of Bloom's Taxonomy on the cognitive level, the following recommendations are briefly suggested:

- A language instructor should pay heed to designing clear learning objectives and for the whole course as well as interesting activities for each lecture. They should describe what students should learn starting from the basic cognitive levels and ending with the higher cognitive levels. Therefore, his learning objectives should not be that imaginary that he cannot carry out in his class. It should rather be more realistic, considerable and consistent with students' capacities and the time allocated.

- Exam questions are recommended to meet all individual differences by submitting a variety of questions representing all the six cognitive levels. Students practice them all each lecture to master the course skills.

- A language instructor is recommended not to focus merely on (LOTs) because of the students' lower motivation to learn better for their weak background in some courses such as in Grammar courses which may affect other courses such as "Writing". The instructors cannot then justify his usage of limited cognitive levels for this reason which may not be satisfactory.

- A language instructor is recommended to include all cognitive levels in his exam questions even the highest levels which require higher level thinking skills if he has trained students on how to think this way.

- Higher order thinking skills (HOTs) should not be replaced by lower order thinking skills (LOTs) by allowing students to know the topics that they will be tested in. In other words, it is not recommended to test students in a seen translation or previously discussed topics of paragraph or Essay Writing for example.

- It deserves mentioning that the existence of lower cognitive levels exam questions is not that bad. It is rather considered a basic knowledge background for higher cognitive levels and it is also important to give the chance for students with limited academic capacities to succeed by submitting correct answers to simple exam questions.

- A language instructor should not work under pressure of time. This may affect the type of exam questions which leads to resorting to direct objective questions such as: True-false, choose the correct answer, complete, matching. These types of questions, however easy to be scored, 
they are time consuming in designing and they rarely measure higher cognitive levels.

- A language instructor should not avoid essay questions for their being time- consuming to score and difficult to identify reliable criteria for scoring. He may rather design questions that require short answers.

- It is recommended to design exam questions in such a variety to suit the testable knowledge included in each question. Hence, a language instructor can skillfully make multiple choice questions measure higher cognitive levels by increasing the distractors in order to diminish the guesses. Similarly, he can do the same in matching questions by increasing the number of items in the answer column. Moreover, he can make true-false questions measure higher cognitive levels and not a matter for guessing if the question requires justifying the given answer.

- A language instructor should always remember that the questions which are easy to write are difficult to grade and the questions which are timeconsuming in writing are easier to grade. Therefore, he/or she should balance his allocated time and the testable knowledge.

-A language instructor is recommended to make the stem of exam questions include "only the information needed to make the problem clear and specific and "avoid the use of negatives in the stem "(Piontek, 2008) and use only when he is measuring whether the respondent knows the exception to a rule or can detect errors.

- Because Foreign Languages exam questions lack higher cognitive level for most courses to be studied, it is useful to suggest simple ways to include such higher cognitive level questions. For example, the most famous stem questions for higher cognitive levels such as Analysis is to ask the students in the question root to find the errors (i.e. in style, Grammar, Syntax...etc.) in a specific paragraph or passage. At the Synthesis level for example this can be carried out by asking students to submit a plan of his own for providing a specific idea or concept. As for the Evaluation level, a language instructor can simply ask students, in the exam questions stem, to determine the weakness points and strength points for a specific idea or project or suggest alternative solutions for specific problems proposed. 


\section{Nehad Rabe'a Elbehiry}

\section{References}

- seels \& Glsgow (1990). Exercises in instructionaldesign. Columbus OH: : Merrill Publishing Company.

- Activities at various cognitive levels of learning. (2014, 9 31). Retrieved from http://enpub.fulton.asu.edu/mcneill/blooms.htm

- Anderson, L. a. (2001). A Taxonomy for Learning, Teaching and Assessing: a Revision of Bloom's Taxonomy of Educational Objectives. NewYork: Longman.

- Anderson, L. a. (2001). educational technology and mobile learning. Retrieved from http://edorigami.wikispaces.com/Bloom\%27s+Digital+Taxonomy

- Anderson, L. K. (2014, 10 10). A Taxonomy for Learning, Teaching, and Assessing: A Revision of Bloom's Taxonomy of Educational Objectives, Abridged Edition. Retrieved from http://www.nwlink.com/ Donclark/hrd/bloom.html\#revised

- Automated analysis of exam questions according to bloom's taxonomy, Nazalia Omar et al (2011) Elsevier Ltd . doi: 10.1016/j.sbspro.2012.09.278

- BernarBernard, H. R. ((1996)). Qualitative data, quantitative analysis., . The Cultural Anthropology Methods Journal, 8 (1), 9-11.

- Bernard, H. R. ((1998)). Text analysis: Qualitative and quantitative methods. . Walnut Creek, CA: AltaMira Press.

- Bloom, B. (2014, 9 31). Asking thinking questions. Retrieved from http://www.pedagoo.org/wp-content/uploads/2012/09/askin-thinking-Qs.png

- Bloom, B. S. (1956). Taxonomy of Educational Objectives: Handbook . London: Longmans Green and Co. Ltd.

- Bloom's taxonomy. (2014, 9 30). Retrieved from http://julietovar.edublogs.org/files/2011/05/blooms-taxonomy-1k4snjn.JPG

- Clark, D. ((2009)). Bloom's Taxonomy of Learning Domains - The Three Types of Learning. Retrieved 10 6, 2014, from http://www.nwlink.com/ Donclark/hrd/bloom.html

- Cutrone, L., \& Chang, M. (2010). Automarking: Automatic Assessment of Open Questions, 2010 10th IEEE International Conference on Advance Learning Technologies. 143-147.

- Forehand, M. (2005). Bloom's taxonomy: Original and revised.. In M. Orey (Ed.), Emerging perspectives on learning, teaching, and technology. Retrieved from

http://epltt.coe.uga.edu/index.php?title=Bloom\%27s_Taxonomy http://epltt.coe.uga.edu/:

- Glasgow, S. a. (1990). Exercises in instructionaldesign. Columbus OH:: Merrill Publishing Company.

- Jones, K., L. J., Harland, J., Reid, J., \& Bartlett, R. (2009). Relationship between examination questions and bloom's taxonomy. Frontiers in Education Conference, 2009. FIE '09. 39th IEEE (pp. 1-6). San Antonio, TX: IEEE. doi:10.1109/FIE.2009.5350598 
- Krathwohl, D. B. ((1964)). Taxonomy of educational objectives: HandbookII: Affective domain. . New York: David McKay Co.

Malon, J. L. ((1988).). The Science of Linguistics in theArt of Translation. Albany, New York:: State Universityof New York Press.

- MASL, m. A. (2014, 10 12). Bloom's Digital Taxonomy. Retrieved from http://www.techlearning.com/article/8670

o:

http://www.maslibraries.org/Resources/Documents/BloomDigital.pdf

- Naomee, I. (2013, February). Reflection of Bloom's Taxonomy in the Learning Outcomes of Secondary Social Science in Bangladesh.

International Journal of Science and Research, India Online (IJSR) ISSN 2319-7064, 2(2), 550-559. Retrieved 10 6, 2014, from https://www.academia.edu/2774360/Reflection_of_Blooms_Taxonomy_in_the _Learning_Outcomes_of_Secondary_Social_Science_Curriculum

- Nkwi, P. N.-c. (2001). Field research into socio-cultural issues:methodological guidlines. Yaounde, Cameroon: International Center for Applied Social Sciences, Research, and Training/UNFPA.

- Piontek, M. E. (2008). BEST PRACTICES FOR DESIGNING AND GRADING EXAMS. CRLT(24). Retrieved November 1, 2015, from http://www.crlt.umich.edu/sites/default/files/resource_files/CRLT_no24.pdf

- Schultz, R. C. (2014, 9 26). Bloom's Taxonomy. Retrieved from http://ww2.odu.edu/educ/roverbau/Bloom/blooms_taxonomy.htm

- Simpson E.J. ((1972)). The Classification of Educational Objectives in the Psychomotor Domain. Washington, DC: Gryphon House.

- Swart, A.J. (2010). Evaluation of Final Examination Papers in Engineering: A Case Study Using Bloom's Taxonomy, IEEE Transactions on Education, (May 2010) Vol. 53, No.2 257-264.

- University of Auckland. (2014, 10 6). Retrieved from Psychomotor domain: http://virtuallythere.wikispaces.com/psychomotor+domain

- 'Question quality': The concept of quality in the context of exam questions' Victoria Crisp, Martin Johnson, and Filio . Constantinou Paper presented at the Association for Educational Assessment in Europe 17th annual conference, Limassol, Cyprus, 3 rd to 5th November 2016.University of Cambridge, local Examination Syndicate.

- W.Eisner, E. (2000, september). BENJAMIN BLOOM. International Bureau of Education, XXX(no.3), 1. Retrieved september 28, 2015, from http://www.ibe.unesco.org/publications/ThinkersPdf/bloome.pdf

- Wyse, S. E. (2011, 9 16). Snap surveys. Retrieved 10 23, 2014, from snap surveys website: http://www.snapsurveys.com/blog/what-is-the-differencebetween-qualitative-research-and-quantitative-research/

- Online dictionary of social sciences. http://bitbucket.icaap.org/ 